\title{
Littérature, humanisme et politique : Ici, sous l'étoile polaire de Väinö Linna
}

\section{Maurice Carrez}

\section{Q OpenEdition}

1 Journals

Édition électronique

URL : http://journals.openedition.org/rbnu/671

DOI : $10.4000 /$ rbnu. 671

ISSN : 2679-6104

Éditeur

Bibliothèque nationale et universitaire de Strasbourg

\section{Édition imprimée}

Date de publication : 1 novembre 2017

Pagination : 44-47

ISBN : 9782859230678

ISSN : 2109-2761

\section{Référence électronique}

Maurice Carrez, «Littérature, humanisme et politique : Ici, sous l'étoile polaire de Väinö Linna », La Revue de la BNU [En ligne], 16 | 2017, mis en ligne le 01 juillet 2019, consulté le 14 décembre 2020 URL : http://journals.openedition.org/rbnu/671; DOI : https://doi.org/10.4000/rbnu.671

\section{(c) (i) (8)}

La Revue de la BNU est mise à disposition selon les termes de la Licence Creative Commons Attribution - Pas d'Utilisation Commerciale - Partage dans les Mêmes Conditions 4.0 International. 


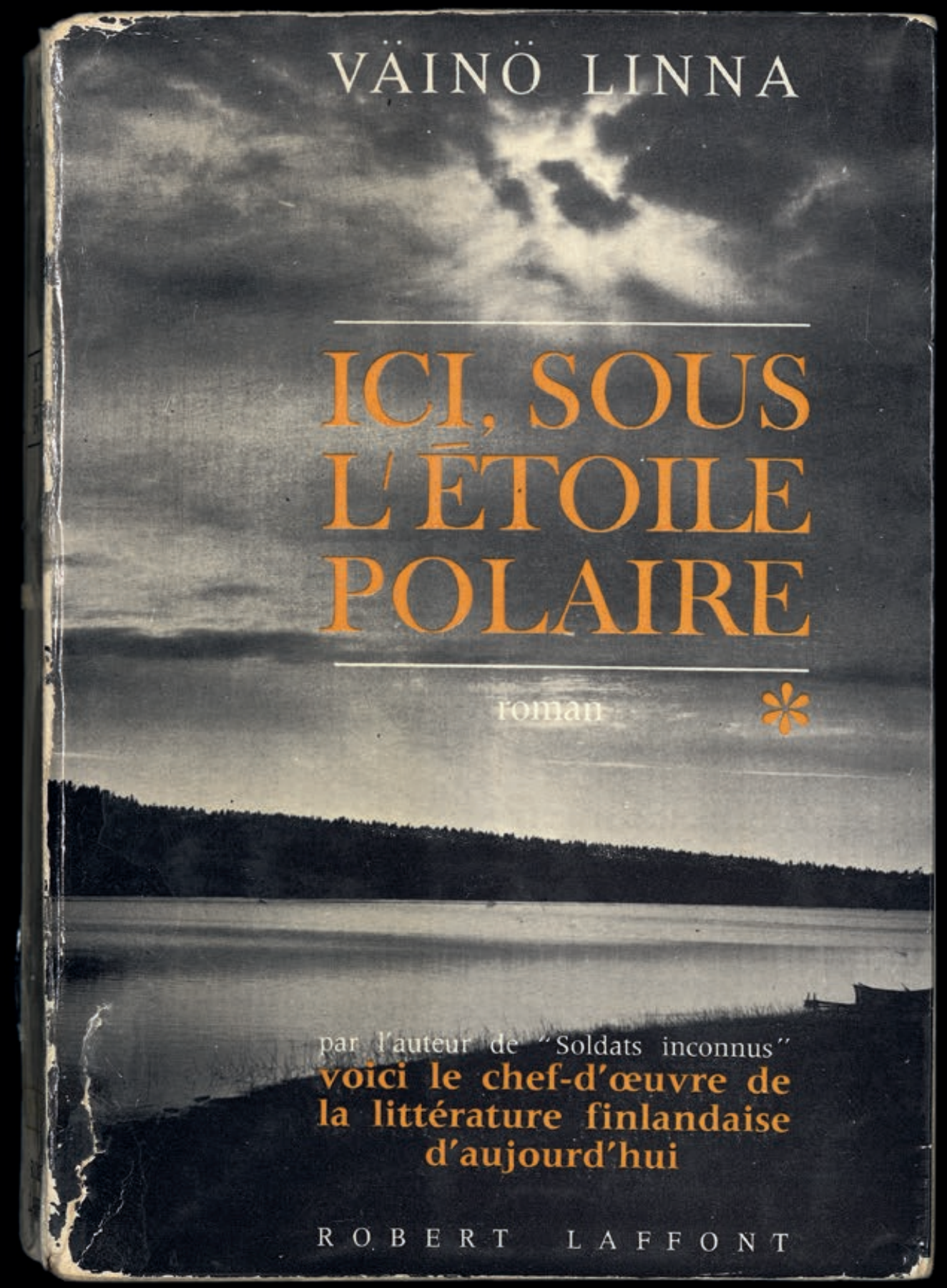

Väinö Linna, Ici, sous l'étoile polaire, Paris, Robert Laffont, traduit du finnois par Jean-Jacques Fol, tome 1, 1962 ; tome 2, « Les gardes rouges de Tampere », 1964 
FINLANDE

\section{LITTÉRATURE, HUMANISME ET POLITIQUE : \\ ICI, SOUS L'ÉTOILE POLAIRE \\ DE VÄINÖ LINNA}

PAR MAURICE CARREZ

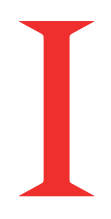

1 est des livres dont la sortie constitue un véritable événement et suscite des polémiques révélant les tensions sous-jacentes de la société. Ici, sous l'étoile polaire (Täällä Pohjantähden alla en finnois) en fait partie.

Son auteur, Väinö Valtteri Linna (19201992), était le septième enfant d'un ancien métayer devenu boucher pour essayer de nourrir sa nombreuse progéniture. Celui-ci mourut jeune, laissant dans la difficulté sa veuve qui dut travailler dur pour échapper tant bien que mal à la misère. De ce fait, le jeune Väinö dut arrêter tôt ses études pour chercher de l'embauche, bien qu'il eût très vite manifesté un grand amour des livres. À dix-huit ans, il entra aux tissages Finlayson de Tampere, la Manchester du Nord, où il finit par devenir mécanicien. Il continua néanmoins d'assouvir sa passion pour la littérature et le cinéma. Comme tous les Finlandais de son âge, il fut mobilisé pendant toute la durée de la Seconde Guerre mondiale. Il connut l'enfer du front entre 1941 et 1943 avant d'être versé dans une compagnie d'instruction. Il mit à profit cette douloureuse expérience pour rédiger ses premiers manuscrits. Deux livres parurent en 1946 et 1948, mais c'est son roman de guerre, Soldats inconnus (Tuntematon sotilas), sorti des presses en 1954, qui le fit connaître du grand public et lui permit de se consacrer entièrement à l'écriture. Il s'attaqua ensuite à un autre sujet brûlant, celui de la guerre civile de 1918, de ses causes et de ses conséquences. Passionné d'histoire et ayant eu dans sa jeunesse l'occasion de fréquenter directement des acteurs de cette période, il voulait essayer de comprendre ce drame affreux qui avait fait trente-cinq mille victimes, dont plus de vingt mille au cours d'une répression atroce menée par les blancs ${ }^{1}$ vainqueurs. Il avait aussi en tête de dépassionner les débats afin de réconcilier deux Finlande(s) qui se tournaient encore le dos.

L'entreprise, commencée à la fin des années 1950 (les trois tomes parus en finnois datent respectivement de 1959, 1960 et 1962), n'était pas facile. Certes il y avait eu, au moment de la guerre d'hiver de 1939-1940, une première phase de rapprochement entre les deux camps plus ou moins téléguidée par le pouvoir au nom de la réconciliation patriotique, mais les tensions nées des procès d'après-guerre (contre ceux qui étaient accusés d'avoir favorisé l'alliance avec l'Allemagne) et 
de la guerre froide avaient à nouveau jeté de l'huile sur le feu. Ainsi, au sein du puissant parti social-démocrate, le retour aux affaires en 1957 de l'ancien ministre des Affaires étrangères et des Finances Väinö Tanner, condamné lors des procès de 1945, avait provoqué une scission d'une partie de la gauche et relancé la polémique sur son attitude « droitière » pendant la guerre civile et l'entre-deux-guerres. Le souvenir des massacres restait toujours vif dans la mémoire collective. De plus, l'enseignement officiel de l'histoire était encore marqué par un manichéisme conservateur que seuls de rares chercheurs commençaient à vouloir dépasser. La crise diplomatique dite des «gels nocturnes », déclenchée à l'automne 1958 entre les autorités soviétiques et finlandaises à cause de la présence dans le gouvernement Fagerholm de partisans de Tanner, n'était pas faite non plus pour ramener de la sérénité, de même qu'une nouvelle pression soviétique à l'automne 1961 pour mettre en garde l'opposition au président Kekkonen contre toute remise en cause du " traité d'amitié » de 1948. Les rouges de 1918 étant assimilés dans la doxa blanche aux bolcheviks, cela ne pouvait que renforcer les vieux préjugés sur le caractère « criminel » du soulèvement.

Väinö Linna refusa d'emblée d'adopter un point de vue partisan. Il voulait montrer comment des injustices et des humiliations sociales pouvaient créer une atmosphère favorable à la révolte, sans prendre le ton du contempteur, mais sans taire non plus la mesquinerie des possédants. Il ne souhaitait pas plus sombrer dans la victimisation systématique des vaincus de la guerre civile ; il chercha donc à donner à ses personnages, en particulier au héros central du roman, le métayer Axel Koskela, une véritable épaisseur psychologique afin de les montrer sous un jour humain, avec leurs forces et leurs faiblesses. De ce point de vue, la galerie de portraits présentée dans le roman ouvre un très large éventail, allant de la brute sanguinaire au «brave gars» victime d'événements qui le dépassent bien qu'il en soit acteur, du politicien chevronné à l'idéaliste un peu naïf, du leader à la force de caractère affirmée au suiveur plus ou moins couard... Le fait de prendre pour scène centrale la vie d'une petite communauté villageoise de métayers et de petits paysans entretenant des rapports fluctuants avec le grand propriétaire de la commune, un baron svécophone ${ }^{2}$ oscillant entre paternalisme et autoritarisme, et un pasteur de bonne volonté que sa femme pousse à exploiter davantage ses métayers, donne au roman un parfum d'authenticité. Ce faisant, Linna montre aussi une réelle connaissance des subtilités politiques de l'époque ; il parvient ainsi à rendre compte de la diversité des positions et des choix au moment décisif du soulèvement. Il sait aussi parfaitement décrire l'atmosphère de la défaite finale et la répression parfois aveugle qui s'ensuivit. Sensibles, les pages qui y sont consacrées ne sombrent pas non plus dans la sensiblerie. De ce fait, le récit reste à une distance suffisante pour être convaincant.

Le traducteur français, Jean-Jacques Fol, futur professeur d'histoire contemporaine puis président de l'Université Paris VII Jussieu, avait une grande familiarité avec la langue finnoise, acquise lors d'un séjour prolongé à Helsinki. Il sut rendre compte des nuances de l'œuvre et de son intensité dramatique. Il est dommage que les éditions Laffont n'aient pas accepté, pour des raisons sans doute financières, la traduction du troisième volume qui traitait de l'entre-deux-guerres et de l'époque très dure du mouvement de Lapua.

Quoi qu'il en soit, cette œuvre de Linna connut en Finlande un énorme retentissement. Elle contribua à faire sortir les rouges du ghetto dans lequel on les maintenait et à donner de leur combat une image moins caricaturale, voire empreinte de dignité. La critique fut en général très positive, tant en Finlande qu'en Suède, bien que certains milieux conservateurs, en particulier Edwin Linkomies, ancien premier ministre des années 1943-1944, condamné en 1945 parce que partisan d'une ligne pro-allemande, mais aussi professeur au département de littérature romane de l'Université d'Helsinki, l'eussent trouvée trop manichéenne. Dans la foulée, au milieu des années 1960, la publication de l'étude pionnière du professeur Jaakko Paavolainen sur les violences politiques des années 1917-1920 ouvrit la voie à des études scientifiques sur la période. Un peu plus tard, la victoire électorale d'une gauche ayant retrouvé le chemin de l'unité fit aussi beaucoup, au niveau officiel, pour une réévaluation de cette période terrible de l'histoire finlandaise. En ce sens, Väinö Linna, écrivain populaire de génie, peut être considéré comme un véritable pionnier de la réconciliation finno-finlandaise.

\footnotetext{
NOTES

1- «Blancs » et « rouges » désignent, pour ce qui concerne la guerre civile finlandaise, respectivement les conservateurs et les sociaux-démocrates.

2- Parlant suédois.
} 


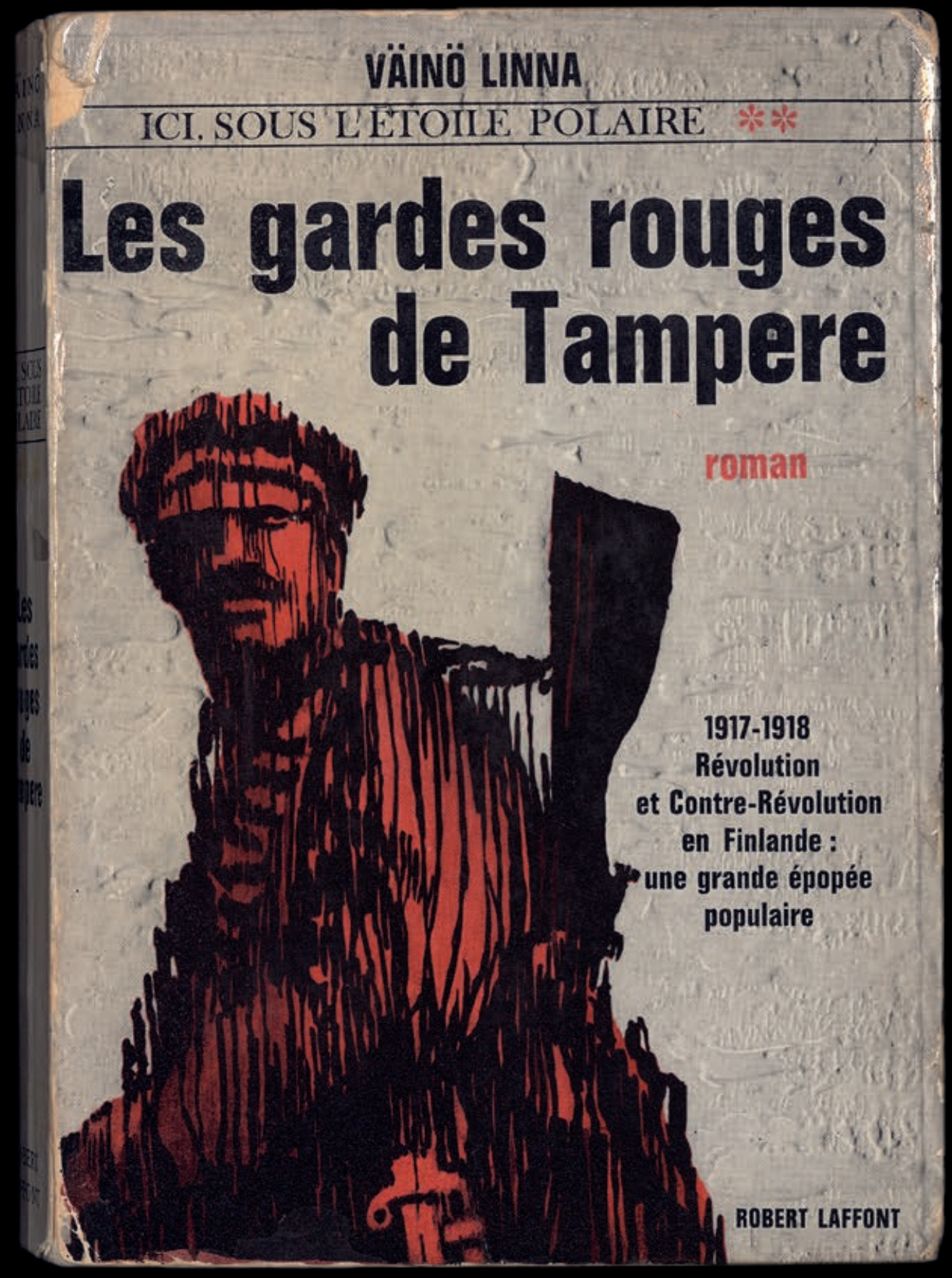

